\title{
Arterial and end-tidal Carbon Dioxide Tension Changes during Spinal Anaesthesia in Upper Abdominal Laparoscopic Surgeries: A Comparison with General Anaesthesia
}

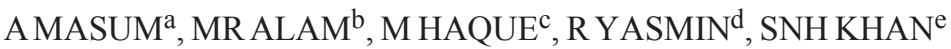

\begin{abstract}
Summary:
Nowadays, laparoscopic surgeries are being performed under subarachnoid block (SAB) safely.

Aims: This study was to compare the arterial and end-tidal carbon dioxide $\left(\mathrm{CO}_{2}\right)$ tension changes during spinal and general anaesthesia (GA) in $\mathrm{CO}_{2}$ pneumoperitoneum for upper abdominal laparoscopic surgeries.
\end{abstract}

Settings and Design: This was a prospective randomized comparative clinical study.

Materials and Methods: Eighty patients posted for upper abdominal laparoscopic surgeries were randomly allocated to two groups either to receive standard GA or lumbar $S A B$.

Results: The demographic profiles of both the groups were comparable. The $\mathrm{PaCO}_{2}$ was increased gradually and sustained at its peaks within $20 \pm 4.37$ minutes in both the groups. The mean $\pm S D$ revealed to be higher in Group $B$

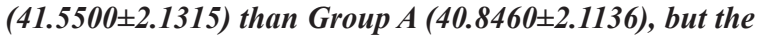
difference between the two was not statistically significant $(P=0.6142)$. There was a gradual increase in $\mathrm{ETCO}_{2}$ over the initial $10 \pm 2.07$ minutes and reached a plateau within $20 \pm 5.74$ minutes in both the groups and declined faster

Introduction:

Laparoscopic surgery has turned into a typical surgical practice in late decades ${ }^{1}$. Initially, all the laparoscopic procedures were being performed customarily under general anaesthesia $(\mathrm{GA})^{2}$. Later on, the laparoscopic

a. Dr. Abdullah Masum, Department of Anaesthesiology, Combined Military Hospital, Dhaka, Bangladesh.

b. Dr. Md. Rabiul Alam, Department of Anaesthesiology, Combined Military Hospital, Dhaka, Bangladesh.

c. Dr. Mozibul Haque, Dhaka, Bangladesh

d. Dr. Rubina Yasmin, NIO, Dhaka, Bangladesh

e. Dr. Shah Newaz H Khan, Department of Anaesthesiology, Combined Military Hospital, Dhaka, Bangladesh.

Address of Correspondence: Dr. Abdullah Masum, Department of Anaesthesiology, Combined Military Hospital, Dhaka, Bangladesh. Phone numbers: +8802-01711061473, E-mail: amasum1973@gmail.com Received: 30 November, 2017

Accepted: 09 October, 2018 after deflation of pneumoperitoneum in $S A B$ group. The mean $\pm S D$ was found to be higher in Group $B$ (33.923 \pm 1.642$)$ than Group A (33.408 \pm 1.772$)$, but it was also not statistically significant $(P=0.4492)$. The difference of the arterial blood $\mathrm{pH}$ between the groups was not statistically significant. Three (7.5\%) patients developed transient urinary retention and 2 (5\%) patients suffered from post-dural puncture headache in $S A B$ group.

Conclusions: Arterial and end-tidal $\mathrm{CO}_{2}$ tension changes during upper abdominal laparoscopic surgery under $S A B$ remain within physiological limit and comparable to the $\mathrm{CO}_{2}$ tensions under GA. However, per-operative complications in SAB are greater, while it is lesser in postoperative period in comparison to $G A$. SAB may be adopted in ASA physical status I patients with proper preoperative counselling.

Key-words: Upper abdominal surgery, Laparoscopic surgery, Subarachnoid block, General anaesthesia, $\mathrm{CO}_{2}$ tension changes.

(J Bangladesh Coll Phys Surg 2019; 37: 13-18)

DOI: http://dx.doi.org/10.3329/jbcps.v37i1.39282

gynaecological interventions were shown safe under subarachnoid block (SAB) with or without epidural analgesia ${ }^{3}$. However, the reception of regional anaesthesia (RA) has risen as an alternative choice recently for even upper abdominal laparoscopy. Various reports in the literatures suggest the safety of the use of spinal, epidural and combined spinal-epidural anaesthesia in laparoscopic procedures ${ }^{4}$. Some centres have been using SAB as their first preference in laparoscopic surgery for a long time ${ }^{5}$. The benefits of a cognizant patient and usually an uneventful recuperation in one hand and the assurance from potential entanglements of GA then again are the principle explanations behind selecting $\mathrm{SAB}$ as a first decision.

Carbon dioxide pneumoperitoneum induces significant hemodynamic changes intra-operatively. The majority 
of pathophysiological changes is related to cardiorespiratory and cerebrovascular system and is caused by high intra-abdominal pressure due to $\mathrm{CO}_{2}$ insufflations and hypercapnia resulted from increased peritoneal absorption of $\mathrm{CO}_{2}$. It causes significant but promptly manageable hemodynamic changes even in the patients belonging to American Society of Anesthesiologists (ASA) physical status I and $\mathrm{II}^{6}$. The respiratory changes during lower abdominal laparoscopic procedures under SAB were analyzed ${ }^{3}$; but in PubMed search, no invasive study was found on respiratory parameters in upper abdominal laparoscopic procedures under SAB. As such, the present study was designed to assess and compare the arterial and end-tidal carbon dioxide tension changes between the patients undergoing SAB and the patients receiving standard GA for upper abdominal laparoscopic surgeries.

\section{Materials and Methods:}

This prospective, randomized comparative study was conducted at Combined Military Hospital Dhaka, a tertiary level hospital within a period of one year from July 2015 to June 2016. After getting due approval of the Hospital Ethical Committee, 80 patients of both genders, scheduled for routine upper abdominal laparoscopic surgeries, aged from 15 to 65 years, belonging to ASA physical status I and II were enrolled randomly along with their prior informed consent (Figure 1). The exclusion criteria were: (a) Cases with

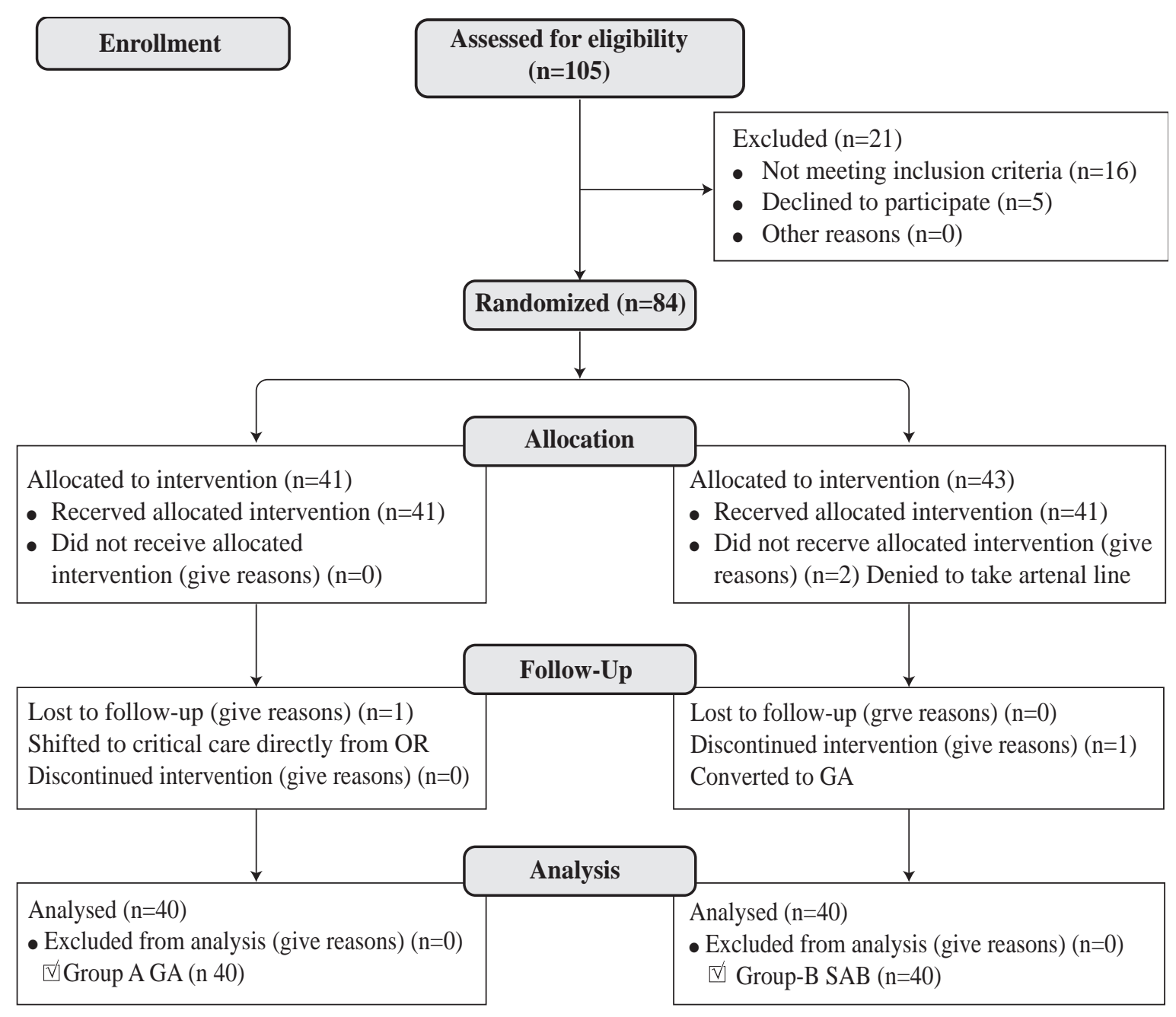

Fig.-1: Consort diagram 
acute inflammation (b) Anxiety prone patients/ diagnosed psychological morbidity (c) Bleeding disorders (d) Local spinal deformity which precluded safe spinal anaesthesia (e) Cases of chronic obstructive pulmonary disease (f) Surgeries with duration of over one hour. The patients were divided into two groups of 40 s by card sampling method.

Group A received standard GA with propofol $2 \mathrm{mg} / \mathrm{kg}$, fentanyl $1.5 \mathrm{mcg} / \mathrm{kg}$ for induction; suxamethonium 1.5 $\mathrm{mg} / \mathrm{kg}$ for intubation; halothane, nitrous oxide, oxygen and vecuronium bromide for maintenance. The respiratory rate was adjusted to maintain $\mathrm{ETCO}_{2}$ between 32 and $36 \mathrm{mmHg}$. Residual neuromuscular blockade was antagonized with $0.05 \mathrm{mg} / \mathrm{kg}$ of neostigmine and $0.2 \mathrm{mg} / \mathrm{kg}$ of atropine at the end of the surgery. The patients were tried to extubate as smooth as to ensure an uneventful recovery.

Group B received lumber SAB in sitting position using 25G Quincke Babcock spinal needle at $\mathrm{L}_{2}-\mathrm{L}_{3}$ interspace with all aseptic measures. A combination of $15 \mathrm{mg} 0.5 \%$ hyperbaric bupivacaine and $25 \mathrm{mcg}$ fentanyl was administered in the lumbar subarachnoid space. The patients were then placed in supine position with 15 degree head down tilt to achieve the sensory blockade upto $\mathrm{T}_{5}$ dermatome (level of block was tested by pin prick stimulus) while the abdomen was prepared for Veress needle insertion simultaneously.

Group A patients were attached with $\mathrm{ETCO}_{2}$ sensors which was fixed in between the endotracheal tube and the breathing circuit (Bain); and the $\mathrm{ETCO}_{2}$ sensors were fixed on a soft sealing transparent facemask which was secured air tight over the faces of group B patients.

In both the groups, a 20-gauze polyurethane catheter was established in the left radial artery temporarily for periodical sampling of arterial blood in order to estimate the $\mathrm{pH}$ and $\mathrm{PaCO}_{2}$ at an interval of 15 minutes. Pneumoperitoneum was produced by insufflating $\mathrm{CO}_{2}$ gas and the intra-abdominal pressure was adjusted to have a comfortable working field [mean $10( \pm 2) \mathrm{cm}$ $\left.\mathrm{H}_{2} \mathrm{O}\right]$. Baseline heart rate, blood pressure, respiratory rate $\& \mathrm{SpO}_{2}$ were noted in all patients. Continuous ECG $\&$ pulse oximetry, noninvasive blood pressure, and $\mathrm{ETCO}_{2}$ were recorded using multiparameter monitor every 5 minutes interval during the procedures. Patients of group B (SAB) who complained of neck pain, shoulder tip pain or both and for anxiety and abdominal discomfort were managed by intravenous midazolam $2 \mathrm{mg}$, ondansetron $8 \mathrm{mg}$, tramadol $100 \mathrm{mg}$ and/or ketamine $25 \mathrm{mg}$. Electrocardiogram, pulse oximetry, noninvasive blood pressure were monitored and recorded at 10 minutes interval in the postoperative period. Any intra- and postoperative complications were observed and managed accordingly.

All results were expressed as mean \pm standard deviation (SD) or in frequencies (percentage) as applicable and analyzed using Chi-Squared test for categorical data and unpaired t-test for quantitative data.

\section{Results:}

The demographic profiles of the patients of both the groups were comparable (Table 1). The $\mathrm{PaCO}_{2}$ was increased gradually and sustained at its peaks within $20 \pm 4.37$ minutes in both the groups (Figure 2). The mean \pm SD was revealed to be higher in the patients of

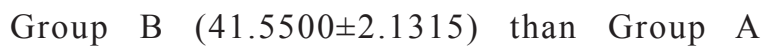
(40.8460 \pm 2.1136$)$, but the difference between the two was not statistically significant $(\mathrm{P}=0.6142)$. There was a gradual increase in $\mathrm{ETCO}_{2}$ over the initial $10 \pm 2.07$ minutes and reached a plateau within $20 \pm 5.74$ minutes in both the groups and declined faster after deflation of pneumoperitoneum in SAB group (Figure 3). The mean \pm SD was found to be slightly higher in the patients of Group B (33.923 \pm 1.642$)$ than Group A $(33.408 \pm 1.772)$, but it was also not statistically significant $(\mathrm{P}=0.4492)$. The difference of the $\mathrm{pH}$ values of the arterial blood between the groups was not statistically significant (Table 2). The incidence of intra- and postoperative complications are shown in Table 3. Three (7.5\%) patients developed transient urinary retention and $2(5 \%)$ patients suffered from post-dural puncture headache in SAB group.

Table-I

\begin{tabular}{lccc}
\multicolumn{4}{l}{ Personal characteristics and duration of surgery } \\
Variables & GroupA & Group B & P-value \\
& $(\mathrm{GA}) \mathrm{n}=40$ & $(\mathrm{SAB}) \mathrm{n}=40$ & \\
\hline Age (years) & $36.20 \pm 4.55$ & $34.03 \pm 5.58$ & 0.0603 \\
Gender (Male/Female) & $21 / 19$ & $17 / 23$ & 1.0000 \\
Weight (kg) & $57.42 \pm 7.36$ & $59.80 \pm 6.71$ & 0.1347 \\
$\begin{array}{l}\text { Duration of surgery } \\
\text { (in hours) }\end{array}$ & $0.958 \pm 0.62$ & $0.947 \pm 0.44$ & 0.9273 \\
\hline
\end{tabular}




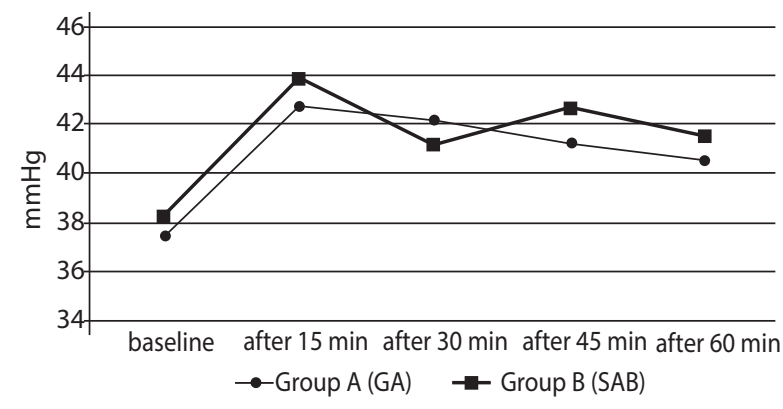

Fig.-2: Arterial $\mathrm{CO}_{2}$ tension changes

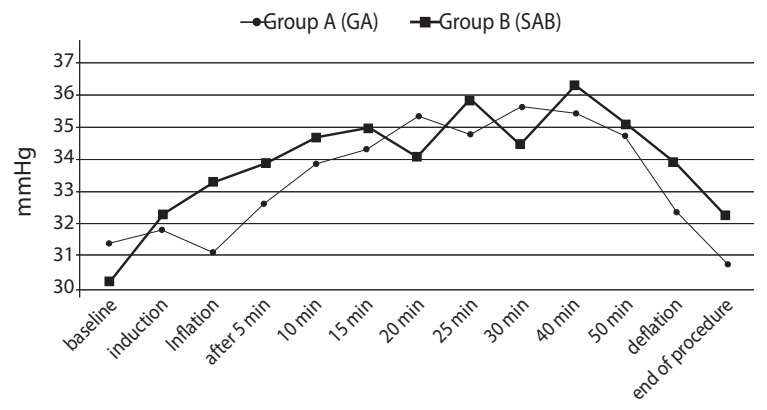

Fig.-3: End-tidal $\mathrm{CO}_{2}$ tension changes

Table-II

\begin{tabular}{|c|c|c|c|}
\hline \multicolumn{4}{|c|}{ Changes in Arterial blood $p H$} \\
\hline Timing & Group A & Group B & P-value \\
\hline Baseline & $7.401 \pm 0.011$ & $7.398 \pm 0.023$ & 0.4590 \\
\hline After $15 \mathrm{~min}$ & $7.396 \pm 0.012$ & $7.389 \pm 0.032$ & 0.1990 \\
\hline After $30 \mathrm{~min}$ & $7.372 \pm 0.064$ & $7.385 \pm 0.098$ & 0.4845 \\
\hline After $45 \mathrm{~min}$ & $7.369 \pm 0.086$ & $7.372 \pm 0.009$ & 0.8269 \\
\hline After $60 \mathrm{~min}$ & $7.350 \pm 0.016$ & $7.363 \pm 0.097$ & 0.4055 \\
\hline \multicolumn{4}{|c|}{ Table-III } \\
\hline \multicolumn{4}{|c|}{ Complications } \\
\hline Period & Complications & $\begin{array}{c}\text { Group A } \\
\text { (GA) }\end{array}$ & $\begin{array}{c}\text { Group B } \\
\text { (SAB) }\end{array}$ \\
\hline \multirow[t]{9}{*}{ Intra-operative } & Discomfort & & $19(47.5 \%)$ \\
\hline & Shoulder tip.'Neck pain & & $11(27.5 \%)$ \\
\hline & Hypertension & $7(17.5 \%)$ & $6(15 \%)$ \\
\hline & Nausea/vomiting & & $5(12.5 \%)$ \\
\hline & Hypotension & $1(2.5 \%)$ & $5(12.5 \%)$ \\
\hline & Delirium & & $4(10 \%)$ \\
\hline & Bradycardia & & $3(7.5 \%)$ \\
\hline & Shivering & & $2(5 \%)$ \\
\hline & Arrhythmia & & $2(5 \%)$ \\
\hline \multirow[t]{6}{*}{ Postoperative } & PONV & $6(15 \%)$ & $15(50 \%)$ \\
\hline & Hypotension & $3(7.5 \%)$ & $1(2.5 \%)$ \\
\hline & Hypoventilation & $1(2.5 \%)$ & \\
\hline & Shivering & $1(2.5 \%)$ & $1(2.5 \%)$ \\
\hline & Urinary retention & & $3(7.5 \%)$ \\
\hline & PDPH & & $2(5 \%)$ \\
\hline
\end{tabular}

\section{Discussion:}

Acid-base alterations occur during laparoscopic abdominal surgeries by $\mathrm{CO}_{2}$ insufflation. A decrease in blood $\mathrm{pH}$ and an increase in $\mathrm{PaCO}_{2}$ are observed during the pneumoperitoneum even with standard controlled ventilation under $\mathrm{GA}^{7}$. This presumption, a real-time discomfort and an instinct fear of an insufflated abdomen were the principle factors of conceding $\mathrm{SAB}$ in laparoscopic surgery. The avoidance of $\mathrm{SAB}$ was also due to its possible suppressive effects on the respiratory muscle functions under increased abdominal pressure. But, it is presently being regarded and honed as a routine and safe anaesthetic technique and recommended for conducting laparoscopic cholecystectomy in hospital setups where cost issue is a major consideration, such as in the developing countries ${ }^{8}$.

This study has compared essentially the arterial and end-tidal carbon dioxide tension changes during $\mathrm{SAB}$ with GA in upper abdominal laparoscopic surgeries. The changes in $\mathrm{pH}$ of arterial blood and the comparison of intra- and postoperative complications were the secondary outcomes. The values of both $\mathrm{PaCO}_{2}$ and $\mathrm{ETCO}_{2}$ were found to be raised in the patients who underwent $\mathrm{SAB}$ than those who underwent standard GA, but the difference were not statistically significant (Figure $2 \& 3$ ). This findings are complied with another study where no significant changes were observed in the ventilatory variables while on spontaneous ventilation during capnoperitoneum for laparoscopic surgery under epidural anaesthesia ${ }^{9}$. The arterial carbon dioxide level was kept nearly unaltered by increased minute ventilation and respiratory rate during $\mathrm{CO}_{2}$ pneumoperitoneum. One of the proposed explanations is that the intrathecal fentanyl shifting the $\mathrm{CO}_{2}$ response curve to the left.

In our study, the $\mathrm{PaCO}_{2}$ and the $\mathrm{ETCO}_{2}$ were elevating till $20 \mathrm{~min}$ in both the groups and stabilised thereafter without any further increment till the decompression of the capnoperitoneum. This duration of increase was observed to be 5 min more in comparison with the finding in lower abdominal laparoscopy ${ }^{3}$. The greater surface area of the upper abdominal peritoneum and the increased absorption of peritoneal fluid in the subdiaphragmatic area could be certain explanations, but not yet settled ${ }^{10}$. We observed no further increase of 
$\mathrm{PaCO}_{2}$ and $\mathrm{ETCO}_{2}$ tensions after 20 min which is reasonably conformed to another study where there was no demonstrable increase after the 15th min of capnoperitoneum in pelvic laparoscopy ${ }^{11}$. This results can be justified by the findings of a study where it was confirmed that an intra-abdominal pressure higher than the venous capillary pressure protects from further $\mathrm{CO} 2$ resorption by compressing the venous capillaries of the peritoneum ${ }^{12}$.

We noticed a faster declining of $\mathrm{PaCO}_{2}$ and $\mathrm{ETCO}_{2}$ after deflation of pneumoperitoneum in $\mathrm{SAB}$ group. Because, GA decreases the sensitivity of respiratory rate to hypercarbia which otherwise restored intact in $\mathrm{SAB}$. Berg et al. even demonstrated a further increment of $\mathrm{PaCO}_{2}$ after desufflation of capnoperitonium after laparoscopic cholecystectomy under $\mathrm{GA}^{13}$. Whereas Beazley et al. in their animal study showed that after desufflation, respiratory rate exhibited an uptrend for next $15 \mathrm{~min}$. The changes were within physiologically acceptable limits in those healthy, anaesthetised cats despite no artificial maintenance of minute ventilation ${ }^{14}$.

The changes in arterial blood $\mathrm{pH}$ depicted an initial transient acidity in the patients of SAB group which was negligible (Table 2), but it was reversed quickly and maintained within the normal limits throughout the procedures. The differences of arterial blood $\mathrm{pH}$ between the groups were not statistically significant. These findings are also comparable to the results of the study projected by Critchley et $\mathrm{al}^{15}$ on the patients underwent laparoscopic cholecystectomy under GA and to the reports provided by Ali et $a 1^{16}$. on laparoscopic procedures under SAB.

Intra- and postoperative complications were diverse between the groups (Table III). In intra-operative complications, 7(17.5\%) patients of Group A (GA) developed transient hypertension (Mean arterial pressure $>105 \mathrm{mmHg}$ ) and $19(47.5 \%)$ patients experienced discomfort principally due to shoulder tip/ neck pain $[11(27.5 \%)]$ in Group B (SAB). Kar et al ${ }^{17}$. showed a higher incidence $(88.51 \%)$ of shoulder tip pain during laparoscopic cholecystectomy under $\mathrm{SAB}$ with low-pressure pneumoperitoneum among which $90.08 \%$ were managed by right shoulder massage alone and $9.93 \%$ required additional administration of 100 mg tramadol intravenously. This shoulder tip pain is explained as the attritions due to the physical and chemical stimulation of the diaphragm by capnoperitoneum.

In the SAB group, 3(7.5\%) patients developed urinary retention temporarily and $2(5 \%)$ suffered from PDPH for 2-3 days. Hence, there are reports of no incidence of PDPH following laparoscopic surgery under $\mathrm{SAB}^{3,4,18}$, while Tiwari et $\mathrm{al}^{8}$ found $3(2.72 \%)$ cases and Imbelloni ${ }^{19}$ found $5(1.47 \%)$ cases of PDPH. But, in contrary, Vaghadia et al. observed $38 \%$ of postoperative headache and $70 \%$ of those were postural in nature ${ }^{20}$.

There were some limitations in this study. We have not considered the height and body mass index of the patients which might be contributing factors to the level of central neuroaxial blockade, patients' discomfort and other perioperative complications. The monitoring of intracranial pressure which is affected by hypercarbia and which also may have a causative role to develop patients' per-operative uneasiness could be included in this study. Moreover, this series was quite smaller and selective; so, randomized study on larger scales are recommended to establish that the laparoscopic cholecystectomy under $\mathrm{SAB}$ is significantly safe and sound for the patients.

\section{Conclusions:}

Arterial and end-tidal $\mathrm{CO}_{2}$ tension changes during upper abdominal laparoscopic surgery under SAB remain within physiological limit and comparable to the $\mathrm{CO}_{2}$ tensions under GA. However, per-operative complications in SAB is greater, while it is lesser in postoperative period in comparison to GA. SAB may be adopted in ASA physical status I patients with proper preoperative counselling.

Key Messages: Arterial and end-tidal $\mathrm{CO}_{2}$ tension changes during upper abdominal laparoscopic surgery under $\mathrm{SAB}$ remain within physiological limit and comparable to the $\mathrm{CO}_{2}$ tensions under GA. However, per-operative complications in $\mathrm{SAB}$ are greater, while it is lesser in postoperative period in comparison to GA. SAB may be adopted in ASA physical status I patients with proper preoperative counselling.

\section{References:}

1. Udwadia TE. Laparoscopy in India - a personal perspective. J Minim Access Surg 2005;1:51-2.

2. Bajwa SJS, Kulshrestha A. Anaesthesia for laparoscopic surgery: General vs regional anaesthesia. J Minim Access Surg 2016;12:4-9. 
3. Pusapati RN, Sivashanmugam T, Ravishankar M. Respiratory Changes During Spinal Anaesthesia for Gynaecological Laparoscopic Surgery. J Anaesthesiol Clin Pharmacol 2010;26:475-9.

4. Singh RK, Saini AM, Goel N, Bisht D, Seth A. Major laparoscopic surgery under regional anesthesia: A prospective feasibility study. Med J Armed Forces India 2015;71:126-31.

5. Sinha R, Gurwara AK, Gupta SC. Laparoscopic Surgery Using Spinal Anesthesia. JSLS 2008;12:133-8.

6. Umar A, Mehta KS, Mehta N. Evaluation of Hemodynamic Changes Using Different Intra-Abdominal Pressures for Laparoscopic Cholecystectomy. Indian J Surg 2013;75:284-9.

7. Kwak HJ, Jo YY, Lee KC, Kim YB, Shinn HK, Kim JY.Acid-base alterations during laparoscopic abdominal surgery: a comparison with laparotomy. BJA 2010;105:442-7.

8. Tiwari S, Chauhan A, Chaterjee P, Alam MT. Laparoscopic cholecystectomy under spinal anaesthesia: A prospective, randomised study. J Minim Access Surg 2013;9:65-71.

9. Ciofolo MJ, Clergue F, Seebacher J, Lefebvre G, Viars P. Ventilatory Effects of Laparoscopy Under Epidural Anesthesia. AnesthAnal 1990;70:357-61

10. Pannu HK, Oliphant M. The subperitoneal space and peritoneal cavity: basic concepts. Abdom Imaging 2015;40:2710-22.

11. Wolf JS Jr, Clayman RV, Monk TG, McClennan BL, McDougall EM. Carbon dioxide absorption during laparoscopic pelvic operation. J Am Coll Surg 1995;180:555-60.

12. Blobner M, Felber AR, Gögler S, Feussner H, Weigl EM, Jelen G, et al. The resorption of carbon dioxide from the pneumoperitoneum in laparoscopic cholecystectomy. Anaesthesist 1993;42:288-94.
13. Berg K, Wilhelm W, Grundmann U, Ladenburger A, Feifel G, Mertzlufft F. Laparoscopic cholecystectomy - effect of position changes and $\mathrm{CO} 2$ pneumoperitoneum on hemodynamic, respiratory and endocrinologic parameters. Zentralbl Chir 1997;122:395-404.

14. Beazley SG, Cosford K, Novakovski TD. Cardiopulmonary effects of using carbon dioxide for laparoscopic surgery in cats. Can Vet J 2011;52: 973-8.

15. Critchley LA, Critchley JA, Gin T. Haemodynamic changes in patients undergoing laparoscopic cholecystectomy: measurement by transthoracic bioimpedance. Br J Anaesthesia 1993;70:681-3.

16. Ali Y, Elmasry MN, Negmi H, Al Ouffi H, Fahad B, Rahman SA. The feasibility of spinal anesthesia with sedation for laparoscopic general abdominal procedures in moderate risk patients. Middle East J Anesthesiol 2008;19:1027-39.

17. Kar M, Kar JK, Debnath B. Experience of Laparoscopic Cholecystectomy Under Spinal Anesthesia with Low-pressure Pneumoperitoneum - Prospective Study of 300 Cases. Saudi J Gastroenterol 2011;17: 203-7.

18. Gurudatta KN, Arif M. A Clinical Study of Comparison between General Anesthesia and Spinal Anesthesia for Lower Abdominal Laparoscopic Surgeries. Sch J App Med Sci 2014;2:1127-33.

19. Imbelloni LE. Spinal anesthesia for laparoscopic cholecystectomy: Thoracic vs. Lumbar Technique. Saudi J Anaesth 2014;8:477-83.

20. Vaghadia H, McLeod DH, Mitchell GW, Merrick PM, Chilvers CR. Small-dose hypobaric lidocaine-fentanyl spinal anesthesia for short duration outpatient laparoscopy. I. A randomized comparison with conventional dose hyperbaric lidocaine. Anesth Analg 1997;84:59-64. 